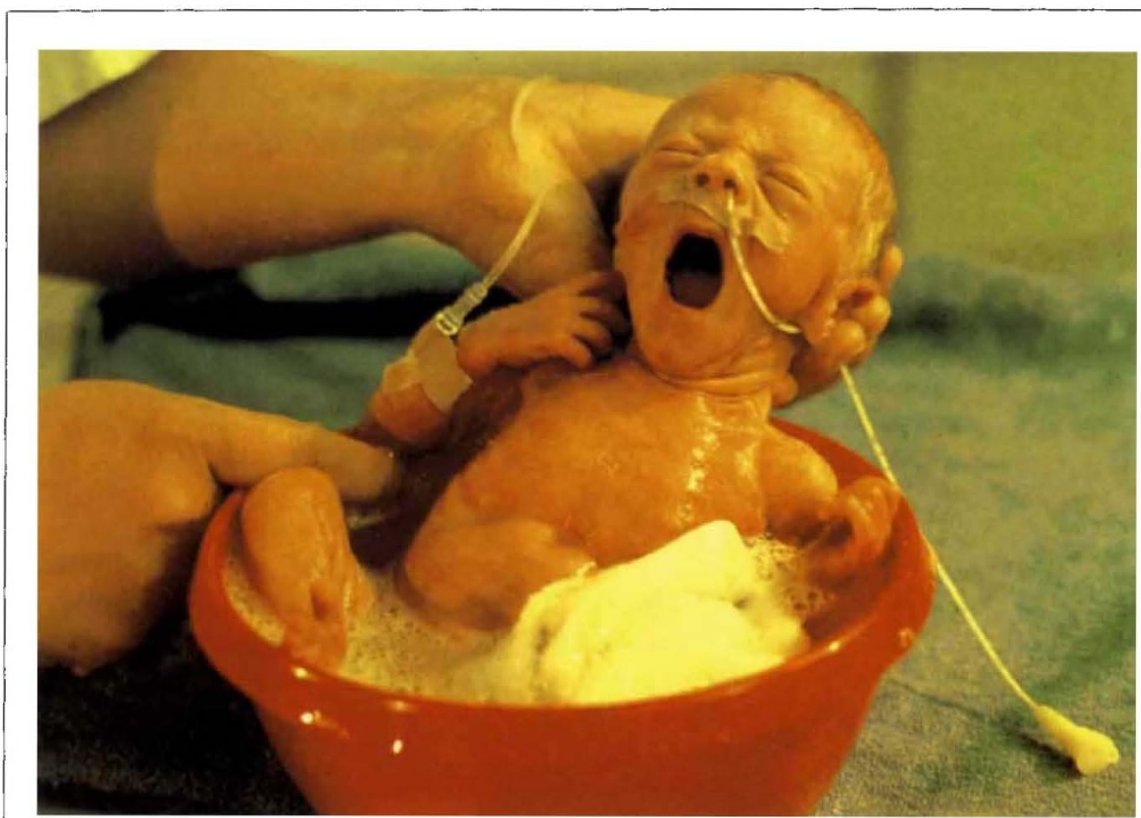

THIS photograph by Ronald Frommann of Stern magazine is one of about 190 prizewinning images brought together in The World Press Photo Yearbook 1994 (Thames and Hudson, £9.95). His pictures of premature infants, some babies weighing as little as $\mathbf{5 0 0}$ grams, were taken at a centre in Dortmund, Germany, that specializes in high-risk births. The photos won second and third prizes in the Science and Technology section of the annual contest, which last year attracted more than 22,000 entries from photojournalists, agencies, newspapers and magazines around the world.

\section{Great minds and neuronal theories}

\author{
Mitchell Glickstein
}

Foundations of Neuroscience. By Marcus Jacobson. Plenum: 1994. Pp. 387. $\$ 79.50, £ 63.60$

NeURoscience is the study of the structure and function of the nervous system. Neuroscientists seek to learn how the brain and spinal cord process sensory signals and control movement, and ultimately to understand the role of the brain in its complex functions of language, thought and volition. Marcus Jacobson examines the foundations of neuroscience, its philosophical basis and its history. He asks what constitutes a theory in neuroscience and what sort of evidence led to the development of its theories. He finds it surprising that little has been written about these questions, and he disagrees with many of the approaches and conclusions of previous work. $\mathrm{He}$ argues that histories often give a false picture of the development of neuroscience as an orderly progression from ignorance to knowledge. Neuroscience, he demonstrates, has always had contradictions and controversies, and many more people have contributed to its development than a few honoured figures.

The author deals extensively with the neuron theory, which is the single most unifying theme of neuroscience. The theory says that the brain and spinal cord are made up of individual elements called nerve cells or neurons, and that neurons are interconnected by contact; their processes do not fuse. Although the usual view is that the circuits formed by neurons can account for all phenomena that neuroscience seeks to understand, Jacobson hints that the exclusive focus on neurons may be mistaken. Glial cells greatly outnumber nerve cells, and perhaps they do more than just support and nourish them.

The author gives ample evidence that the neuron doctrine did not emerge fully blown from the mind of any one person. Rather, it evolved slowly over much of the nineteenth century, beginning with the pioneering work of Purkinjé and Schwann, and culminating with the contributions of Ramón y Cajal and Sherrington. As Jacobson points out, although Cajal and Sherrington strongly supported the doctrine, the evidence remained indirect. The gaps between neuronal processes are below the limits of resolution of the light microscope, so it was only with the greatly increased resolution of the electron microscope that there was final proof that the processes of nerve cells do not fuse.

Jacobson warns against excessive emphasis on the contributions of single individuals. Cajal, he argues, has been put on too high a pedestal. He draws a cartoon of Cajal portrayed as a tiny man perched on the shoulders of a giant Camillo Golgi, another of the great nineteenth-century neurohistologists. Here I part company with Jacobson. Cajal stands head and shoulders above all other neurohistologists before and since. His great textbook on the histology of the nervous system, first written in Spanish about a hundred years ago, still serves as a guide for experimental research on the brain. Cajal's genius is clearest when his writing is compared with that of his contemporaries. None had so clear and lucid a style. None portrayed fundamental concepts of brain structures as deftly as Cajal could with a few diagrams. I remain an unreconstructed hero-worshipper.

Study of the history of neuroscience helps us to recognize both its progress and its limitations. Although advances may be hard to see from day to day, over a longer period the field makes orderly progress. It seems as if each generation of neuroscientists tries to account for the structure and function of the brain completely, with inconsistencies and lacunae papered over. Discoveries are often generalized prematurely. When the electrical activity of peripheral nerves began to be understood, there was an attempt to explain reflexes on the basis of principles derived from study of axonal conduction. Early discoveries of the receptive field properties of single cells in the visual cortex were quickly extrapolated to account for all forms of vision. In both cases the fundamental discoveries remained valid, but the initial enthusiams became tempered with time.

Perhaps the weakest part of the book is the last chapter on ethics in neuroscience. Jacobson presents a list of rules for ethical behaviour in neuroscience - many of them can be assumed under the command "thou shalt not lie". Indeed, lying in science generally reverses the usual scale of morality. In ordinary life it is worse to steal from a friend than to lie to him. Lying in science is the greater crime, because it undermines the basic assumption of the scientific effort. But I knew that.

Jacobson has a broad grasp of the history and the philosophical implications of the field of neuroscience. Although his points are explicitly and clearly made, the book pre-supposes a good deal of knowledge about the field, so it may not be easy for non-neuroscientists to read. All the same, it does an important service by enquiring deeply into the origins and philosophical implications of the underlying ideas of neuroscience.

Mitchell Glickstein is in the Neuroscience and Behaviour Group, Department of Anatomy and Developmental Biology, University College London, Gower Street, London WC1E 6BT, UK. 